\title{
STATUS OF THE BOOSTER INJECTOR FOR THE DUKE FEL STORAGE RING*
}

\author{
M. Busch, S.Mikhailov, M. Emamian, J. Faircloth, S.Hartman, J. Li, V.Popov, G.Swift, V.Vylet, \\ P.Wallace, P.Wang, Y.Wu, FEL Laboratory, Duke University, Durham, NC 27708, USA
}

\author{
N.Gavrilov, G.Kurkin, Yu.Matveev, D.Shvedov, O.Anchugov, N.Vinokurov \\ Budker Institute of Nuclear Physics, Novosibirsk, Russia
}

\section{Abstract}

This paper presents the current status of the booster synchrotron for the Duke Free Electron Laser Laboratory (DFELL) storage ring. The booster will provide full energy injection into the storage ring in a wide energy range from 0.27 to $1.2 \mathrm{GeV}$. When operating the DFELL storage ring as the High Intensity Gamma Source (HIGS) to produce gamma photons above $20 \mathrm{MeV}$ with Compton scattering, continuous electron loss occurs. The top-off mode operation of the booster injector will enable the continuous operation of the HIGS facility by replenishing the lost electrons. The design requirement for a compact booster with the single bunch extraction capability remains a challenge for the machine development. Presently, the booster project is in the installation phase. The magnetic elements, vacuum chambers, injection and extraction kickers have been developed in collaboration with and fabricated at the Budker Institute of Nuclear Physics (BINP), Russia. The diagnostic and control system is being developed at DFELL. The commissioning of the booster synchrotron will start at the end of 2005 .

* Supported by U.S. DoE grant \# DE-FG02-01ER41175

\section{BOOSTER PARAMETERS}

The DFELL booster synchrotron is a compact $31.9 \mathrm{~m}$ circumference machine with race-track shape as shown if Figure 1. It is designed with the capability of delivering up to $4 \mathrm{nC} / \mathrm{sec}$ of electron beam into the storage ring in the top-off mode operation for high flux gamma-ray beam production. The booster parameters are listed in Table 1 .

The booster uses the existing linac as an injector at a beam energy of $270 \mathrm{MeV}$. It is designed primarily for single turn injection. The injection scheme is vertical using a horizontal Lamberson type septum magnet with a static magnetic field. With an existing photocathode gun, the linac allows injection of a single bunch with maximum current of $2 \mathrm{~mA}$. A Linac modification is required to provide multi-bunch operation.

The extraction energy of the booster can vary from 270 $\mathrm{MeV}$ to $1.2 \mathrm{GeV}$. The booster is optimized for single bunch extraction. The booster and the storage ring are fully synchronized for the extraction [6]. The RF frequency of the booster may be tuned independently or be phase-locked to the master oscillator of the main ring. The odd ratio of the harmonic numbers of the booster and

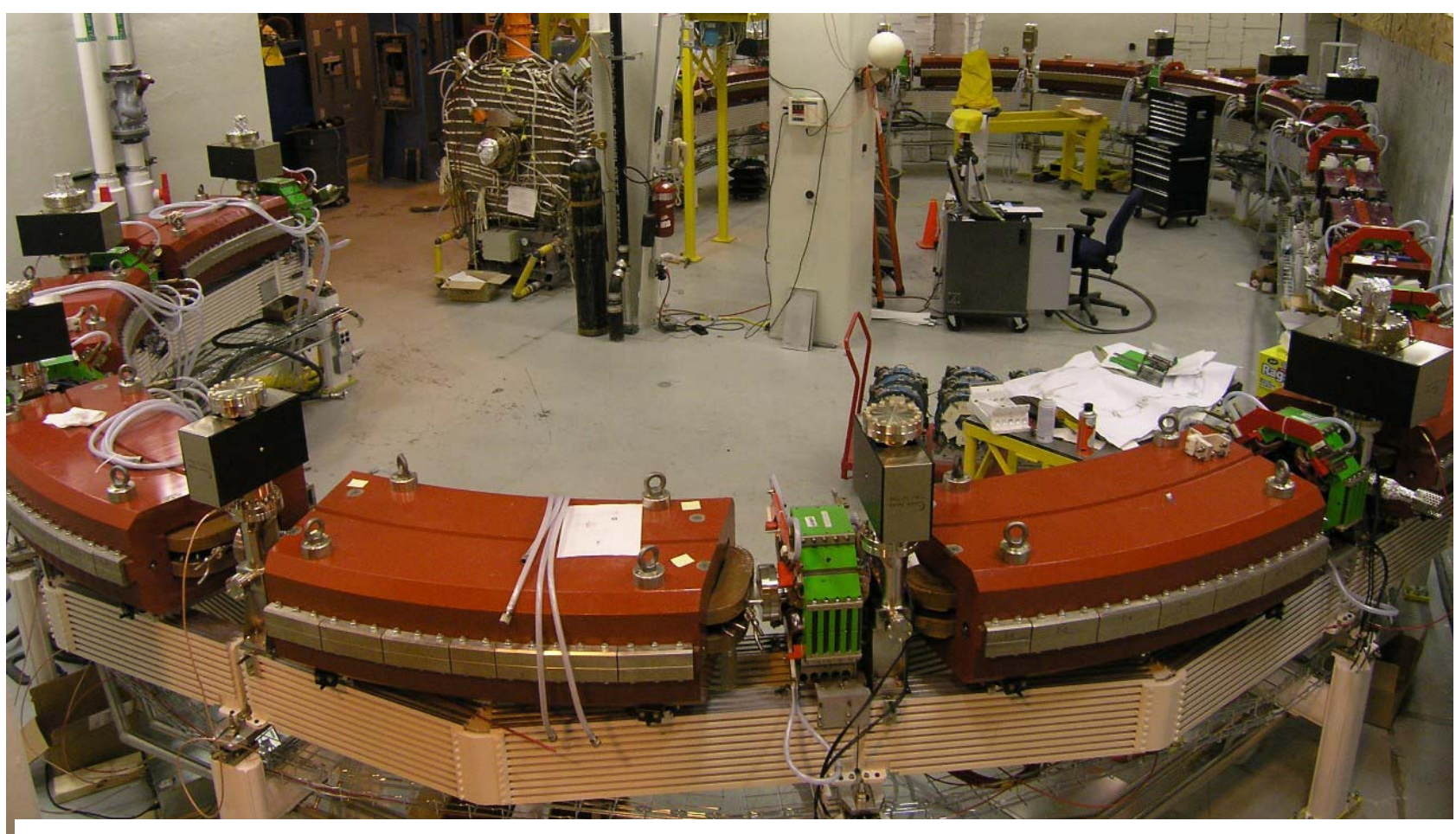

Figure 1: Booster installation status. 
ring, 19/64, provides for extraction of any individual electron bunch from the booster into any selected RF bucket of the storage ring.

The lattice, design and injection features of the booster are described in detail in $[1,2,3,4]$.

Table 1: Booster parameters.

\begin{tabular}{|c|c|c|}
\hline & $\begin{array}{l}\text { Single } \\
\text { bunch }\end{array}$ & $\begin{array}{l}\text { Multi- } \\
\text { bunch }\end{array}$ \\
\hline Maximum beam energy [GeV] & \multicolumn{2}{|c|}{1.2} \\
\hline Injection energy $[\mathrm{GeV}]$ & \multicolumn{2}{|c|}{0.27} \\
\hline Stored beam current $[\mathrm{mA}]$ & $1.5-2$ & 100 \\
\hline Circumference $[\mathrm{m}]$ & \multicolumn{2}{|c|}{31.902} \\
\hline Bending radius [m] & \multicolumn{2}{|c|}{2.273} \\
\hline RF frequency [MHz] & \multicolumn{2}{|c|}{178.55} \\
\hline Harmonic number & \multicolumn{2}{|c|}{19} \\
\hline Nominal operation cycle [sec] & 1.2 & 2.5 \\
\hline Energy rise time, $\min [\mathrm{sec}]$ & \multicolumn{2}{|c|}{0.55} \\
\hline \multicolumn{3}{|c|}{ At maximum energy $E=1.2 \mathrm{GeV}$} \\
\hline Beam emittance $\varepsilon_{x}, \mathcal{E}_{y}[\mathrm{nmrad}]$ & \multicolumn{2}{|c|}{$350 / 15$} \\
\hline Maximum $\beta_{x} / \beta_{y} / \eta_{x}[\mathrm{~m}]$ & \multicolumn{2}{|c|}{$25.4 / 9.4 / 1.4$} \\
\hline Betatron tunes $Q_{x} / Q_{y}$ & \multicolumn{2}{|c|}{$2.43 / 0.46$} \\
\hline Momentum compaction factor & \multicolumn{2}{|c|}{0.153} \\
\hline Natural chromaticity $C_{x} / C_{y}$ & \multicolumn{2}{|c|}{$-1.7 /-3.7$} \\
\hline Damping times $\tau_{x, y} / \tau_{s}[\mathrm{mS}]$ & \multicolumn{2}{|c|}{$3.16 / 1.58$} \\
\hline Energy loss per turn $[\mathrm{KeV}]$ & \multicolumn{2}{|c|}{80.7} \\
\hline Energy spread $\sigma_{E} / E$ & \multicolumn{2}{|c|}{$6.8 \cdot 10^{-4}$} \\
\hline
\end{tabular}

\section{FACILITIES UPGRADES}

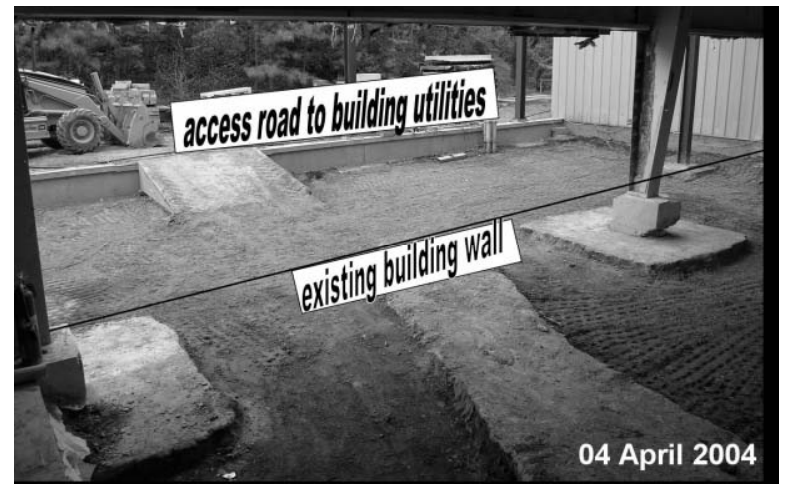

Figure 1: Building expansion construction showing limits of expansion.

The booster upgrade required several changes to the existing facility. The location of existing building utilities such as main disconnect panels, building steam and chilled water, air compressor, DI water system, and transformers limited the maximum dimensions for building expansion. Figure 2 shows how access to these utilities limited the dimensions of the building expansion. These building expansion limits dictated a compact booster design.

A $25^{\prime} \times 55^{\prime}$ building expansion was added to the north east corner of the building to accommodate the booster. The floor of the adjacent interior hallway was removed to pour a 50'x55'x22" thick monolithic slab as a booster machine foundation [8]. A 30'x50'x13' high concrete vault was poured in place on the foundation slab to provide a radiation shielding vault for the booster. The vault has 2' thick walls and a 1' thick roof.

\section{MAGNETIC SYSTEM}

The magnetic system of the booster includes the following:

- 12 bending magnets with parallel edges;

- 8 focusing quadrupoles;

- 8 defocusing quadrupoles;

- injection and extraction septum magnets;

- 4 focusing and 4 defocusing sextupoles;

- 4 vertical orbit trim dipoles;

- 4 horizontal orbit trim dipoles.

One of the primary goals of the lattice and magnet design of the booster was to feed the 12 bending dipoles and 16 quadrupole magnets from the same power supply. This power supply is a modified Trans-Rex PSU similar to that described in [9] with maximum current of $750 \mathrm{~A}$.

The majority of the trim coils in the booster are powered by either a commercial power supply by BiRa Systems, or the Vic-15, designed and fabricated at the DFELL [10].

All the dipoles and quads are laminated and have extensive end chamfers optimized both for the harmonic content and for the fast ramp [2,3]. A detailed description of these magnets is in [5].

Bending dipoles and quadrupole magnets have been fabricated, tested, and magnetically measured at the BINP. Additional mechanical and magnetic measurements have been completed at the DFELL to verify safe transport and repeatable measurements after installation.

\section{VACUUM SYSTEM}

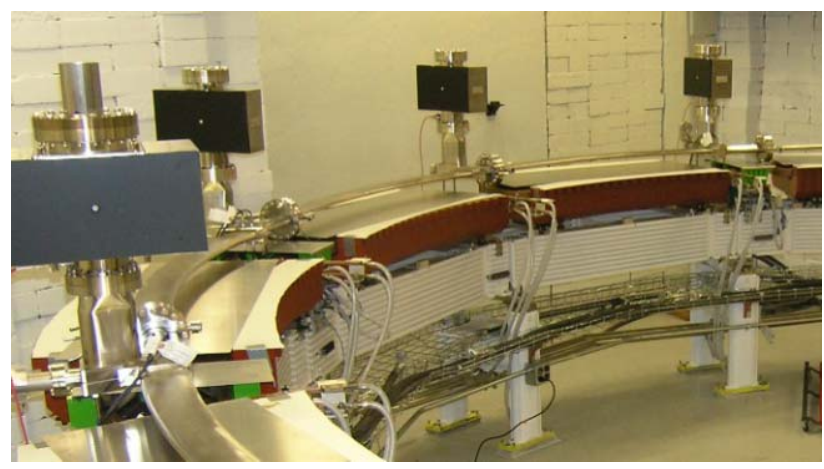

Figure 3: East arc vacuum system after in-situ bakeout.

The booster has a stainless steel vacuum chamber. The arc chamber consists of 6 flanged sections consisting of a $30^{\circ}$ arc of elliptical cross section for the dipole magnet, a welded pump cross and Beam Position Monitor (BPM) button chamber, and a fluted quadrupole chamber. At the center of each arc, the quadrupole chamber is replaced by a convoluted bellows. A synchrotron radiation absorber is incorporated into each arc. At the end of each arc section there is a polished copper absorber tip and opposing 
synchrotron radiation view port The chambers were fabricated at the BINP, and delivered under vacuum. Due to the length and high degree of forming and welding required on each arc chamber, each arc chamber was measured in detail before installation and matched to avoid tolerance stack up. The large ion pumps in the arcs were supplied by a vendor in Russia, but returned when they failed to meet our specifications for base pressure. They were replaced with Gamma Vacuum TiTan ion pumps, 6 each 200 l/s with TSP module, and 6 each 100 $1 / \mathrm{s}$.

The straight section vacuum chambers accommodate the septum magnets, RF Cavity (currently installed, see figure 1), sextupole magnets, dipole corrector magnets, and kicker chambers.

\section{DIAGNOSTICS AND CONTROLS}

Beam diagnostics for the booster and injection lines have been selected with a premium on ease of use and operation. Nine sets of BPM button modules from Bergoz, five insertable screens of DFELL design, and one ceramic break are designed into the vacuum system. The ceramic break will host a Modular Parametric Current Transformer (MPCT), also from Bergoz. One ceramic break in the Linac-to-Booster (LTB) and one ceramic break in the Booster-to-Ring (BTR) vacuum system provide a space for the Bergoz Fast Current Transformers (FCT) at the entrance and exit of the booster.

For machine monitoring, each magnet coil loop DI water return temperature will be affixed with a solid state temperature monitor. For machine protection, each magnet coil loop will be fitted with a Klixon thermal cutoff switch. Each synchrotron radiation absorber loop will be monitored near the heat source by a precision RTD $\left(+/-0.1^{\circ} \mathrm{C}\right)$ to monitor cooling effectiveness.

The controls required for the project will be VME based and run the VxWorks real-time operating system on PowerPC processor single-board computers. The scope of the control system for the booster project includes: controlling and monitoring of the magnet power supplies for transfer lines, booster, and modified north straight section; interface to the RF systems for the booster and storage ring; ramping control; timing delay signals for injection and extraction; monitoring of PPS and MPS systems (including vacuum, temperature, water system, and area radiation monitors); and interface to system diagnostics and instrumentation [6,7].

\section{CONCLUSIONS}

The facility modifications required to accommodate the DFELL booster are complete. The booster arc magnetic elements and vacuum chambers are installed and aligned [8]. The vacuum chambers of the arcs are baked out insitu, the pressure after the bake out is about $10^{-10}$ torr. The installation of the magnets and vacuum chamber for the straight sections is underway. The installation of the RF system is complete. The RF generator is tested at a low power level with RF cavity as a load. The installation of the straight section magnetic and vacuum systems are underway and due to completion summer 2005. A team of scientists and technicians from the BINP will visit DFEL in the summer of 2005 to install and test the kicker system. The Vic-15 trim power supplies will be fabricated and installed in the summer and fall of 2005. The majority of the diagnostics and controls hardware has been procured and will be installed in the summer and fall of 2005. The facility will be shutdown in the fall of 2005 for final connections to the linac and storage ring, with complete system commissioning scheduled for spring, 2006.

\section{REFERENCES}

[1] S.F.Mikhailov, V.N.Litvinenko, P.Morcombe, G.Swift, N.A.Vinokurov, N.G.Gavrilov, Yu.G.Matveev, D.A.Shvedov, "Project of Booster Synchrotron for Duke FEL storage ring", Proc. of the 2001 Part. Acc. Conf., Chicago, 2001, p. 3525-3527.

[2] S.Mikhailov, V.Litvinenko, M. Busch, M. Emamian, S.Hartman, I.Pinaev, V.Popov, G.Swift, P.Wallace, P.Wang, Y.Wu, N.Gavrilov, Yu.Matveev, D.Shvedov, N.Vinokurov, P.Vobly, "Status of the Booster Synchrotron for Duke FEL Storage Ring", Proc. of the 2003 Part. Acc. Conf., Portland, Oregon, 2003. - p. 2273-2275.

[3] S.F.Mikhailov, "Challenges for magnetic design of a compact Booster fed by single power supply", Proc. of the 2003 Part. Acc. Conf., Portland, Oregon, 2003. - p. 2276-2278.

[4] "The Upgrade of the High Intensity Gamma-ray Source”, DOE Technical Design Report, March 2004.

[5] S.Mikhailov, N.Gavrilov, D.Gurov, O.Kiselev, A.Ogurtsov, E.Rouvinsky, K.Zhiliaev, "Dipole and Quadrupole Magnets for the Duke FEL Booster Injector", this proceedings.

[6] G.Ya.Kurkin, S.Hartman, S.Mikhailov, Y.K.Wu, "A New Timing System for the Duke Booster and Storage Ring", this proceedings.

[7] S.Hartman, S.Mikhailov, Y.K.Wu, "A Control System for the Duke Booster Synchrotron", this proceedings.

[8] M.Emamian, M.Busch, S.Mikhailov, G., N.Gavrilov, "Mechanical Alignment of the Booster Injector for the Duke FEL Storage Ring", this proceedings.

[9] V.Popov, S.Hartman, S.Mikhailov, O.Oakeley, P.Wallace, Y.K.Wu, "3 kA Power Supplies for the Duke OK-5 FEL Wigglers", this proceedings.

[10] V.Popov, S.Hartman, S.Mikhailov, O.Oakeley, P.Wallace, Y.K.Wu, "Trim Power Supplies for the Duke Booster and Storage Ring", this proceedings. 